\title{
Transuranium Removal from Hanford AN-107 Simulants using Sodium Permanganate and Calcium
}

by

W. Wilmarth

Westinghouse Savannah River Company

Savannah River Site

Aiken, South Carolina 29808

S. W. Rosencrance

RECEIVED

SEP 112000

OSTI

C. A. Nash

D. P. DiPrete

C. C. DiPrete

DOE Contract No. DE-AC09-96SR18500

This paper was prepared in connection with work done under the above contract number with the U.S.

Department of Energy. By acceptance of this paper, the publisher and/or recipient acknowledges the U.S.

Government's right to retain a nonexclusive, royalty-free license in and to any copyright covering this paper, along with the right to reproduce and to authorize others to reproduce all or part of the copyrighted paper. 


\section{DISCLAIMER}

This report was prepared as an account of work sponsored by an agency of the United States Government. Neither the United States Government nor any agency thereof, nor any of their employees, make any warranty, express or implied, or assumes any legal liability or responsibility for the accuracy, completeness, or usefulness of any information, apparatus, product, or process disclosed, or represents that its use would not infringe privately owned rights. Reference herein to any specific commercial product, process, or service by trade name, trademark, manufacturer, or otherwise does not necessarily constitute or imply its endorsement, recommendation, or favoring by the United States Government or any agency thereof. The views and opinions of authors expressed herein do not necessarily state or reflect those of the United States Government or any agency thereof. 


\section{DISCLAIMER}

Portions of this document may be illegible in electronic image products. Images are produced from the best available original document. 
Westinghouse

Savannah River Company

Alken, SC 29808

October 26, 1999
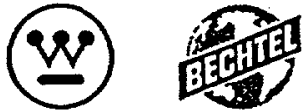

(1

BNFL

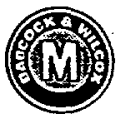

BNF-003-98-0160A

Mr. Mike Johnson

BNFL, Inc.

2940 George Washington Way

Richland, WA 99352

Dear Mike:

RPP-WTP PRIVATIZATION PART B, SRTC WFO-98-003, SUBMITTAL OF "TECHNICAL REPORT: TRANSURANIUM REMOVAL FROM HANFORD AN-107 SIMULANTS USING SODIUM PERMANGANATE AND CALCIUM, BNF-003-98-160, REV. 0"'

Attached please find the "Technical Report: Transuranium Removal from Hanford AN-107 Simulants Using Sodium Permanganate and Calcium, BNF-004-98-160."

The document being transmitted has not been reviewed and approved for release to the public. Please maintain physical control over this document so as to prevent unauthorized access to the information. When this document is approved for release, BNFL will be notified in writing.

Please contact Charles Nash or Steve Wach if you have any questions.

Sincerely,

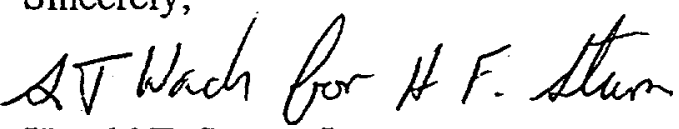

Harold F. Sturm, Jr.

BNFL RPP-WTP Project Manager

Savannah River Technology Center

hfs/sgm

Att.

c: W. R. Wilmarth, 773-42A

C. A. Nash, 773-42A

S. W. Rosencrance, 773-42A

D. P. DiPrete, 773-41A

C. C. DiPrete, $773-41 \mathrm{~A}$

C. T. Randall, 773-42A

B. J. Skwarek, 773-41 A

H. F. Sturm, 773-A

S. T. Wach, 773-42A

BNFL File, 773-41 A, 260 
Transuranium Removal from Hanford AN-107 Simulants Using Sodium Permanganate and Calcium
W. R. Wilmarth
C. A. Nash
S. W. Rosencrance
D. P. DiPrete
C. C. DiPrete

September 22, 1999

Westinghouse

Savannah River Company

Aiken. SC 29808 


\section{DISCLAIMER}

This report was prepared as an account of work sponsored by an agency of the United States Government. Neither the United States Government nor any agency thereof, nor any of their employees, makes any warranty, express or implied, or assumes any legal liability or responsibility for the accuracy, completeness, or usefulness of any information, apparatus, product or process disclosed, or represents that its use would not infringe privately owned rights. Reference herein to any specific commercial product, process or service by trade name, trademark, manufacturer, or otherwise does not necessarily constitute or imply its endorsement, recommendation, or favoring by the United States Government or any agency thereof. The views and opinions of authors expressed herein do not necessarily state or reflect those of the United States Government or any agency thereof.

This report has been reproduced directly from the best available copy.

Available for sale to the public, in paper, from: U.S. Department of Commerce, National Technical Information Service, 5285 Port Royal Road, Springfield, VA 22161, phone: (800) 553-6847

fax: (703) 605-6900

email: orders@ntis.fedworld.gov

online ordering: http://www.ntis.gov/ordering.htm

Available electronically at http://www.doe.gov/bridge

Available for a processing fee to U.S. Department of Energy and its contractors, in paper, from: U.S. Department of Energy, Office of Scientific and Technical Information, P.O. Box 62, Oak Ridge, TN 37831-0062, phone: (865) 576-8401

fax: (865) 576-5728

email: reports@adonis.osti.gov 


\section{Table of Contents}

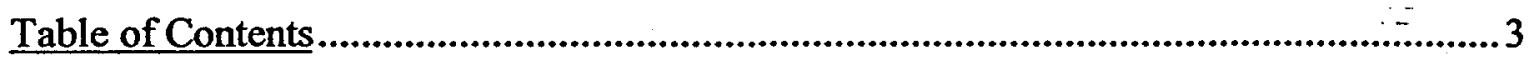

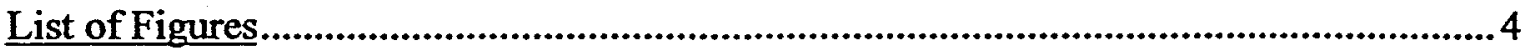

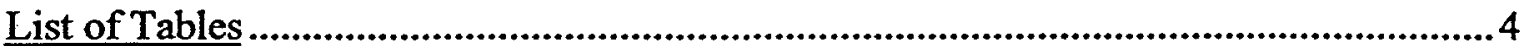

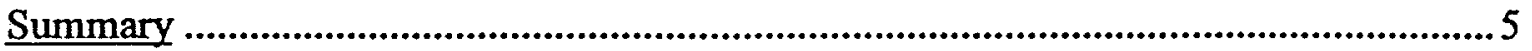

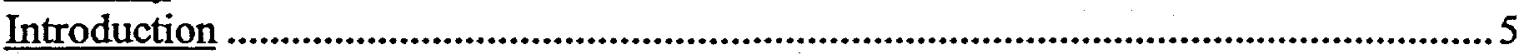

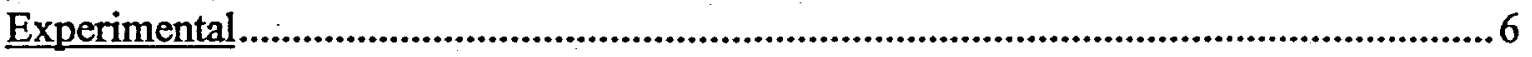

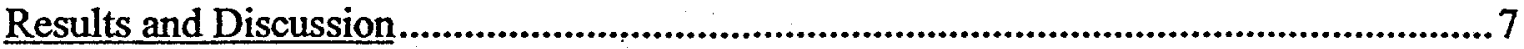

Addition Ferric and Ferrous Precipitation Studies .............................................7 7

Effect of Other Transition Metal Agents and Calcium............................................8

Initial Testing with Sodium Permanganate and Calcium Decontamination..................9

Additional Calcium/Permanganate Tests ............................................................11

Rate of Actinide Removal in Calcium/Sodium Permanganate Decontamination......... 13

Conclusions.............................................................................................................. 15

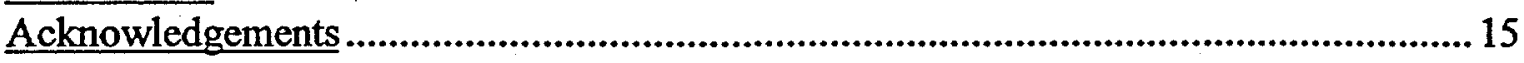

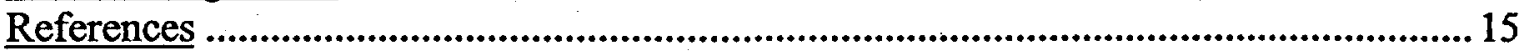




\section{List of Figures}

Figure 1. Decontamination Factors for Ferric/Ferrous Precipitations ...............................8

Figure 2. Filtration Volumes from Transition Tests ..............................................................8

Figure 3. Decontamination Factors for Other Transition Metals.....................................9

Figure 4. Filterability of Permanganate and Calcium Precipitates .........................:-.......10

Figure 5. Decontamination Factors for Permanganate and Calcium Additions ............... 10

Figure 6. Filtrate Volume (mL) from 2 Level Calcium Tests. ........................................11

Figure 7. Decontamination Factors for Additional Calcium and Permanganate Tests.... 12

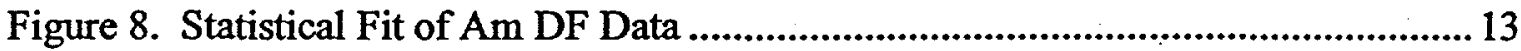

Figure 9. Kinetic Data for Permanganate Decontamination .............................................. 14

Figure 10. Statistical Analysis of Am DF ........................................................................ 14

\section{List of Tables}

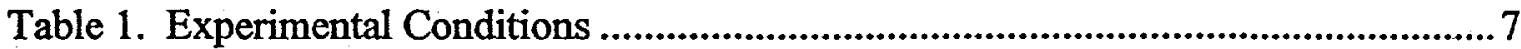

Table 2. Comparison of Actinide DFs at Two Calcium Levels ........................................ 13 


\title{
Transuranium Removal from Hanford AN-107 Simulants Using Sodium Permanganate and Calcium
}

\author{
W. R. Wilmarth, C. A. Nash, S. W. Rosencrance \\ Waste Processing Technology Section \\ D. P. DiPrete and C. C. DiPrete \\ Analytical Development Section \\ Savannah River Technology Center
}

\section{Summary}

Removal of strontium from the complexant-containing wastes (AN-102 and AN-107) had previously been acceptably accomplished by isotopic dilution. Actinide removal using ferric co-precipitation, however, was very problematic from both a processing and a decontamination standpoint. Therefore, a series of tests were performed to identify other potential actinide removal agents and to test these agents at various concentrations. The results of this work provide the following conclusions.

- Addition of sodium permanganate to an AN-107 simulant produced a filterable precipitate in the presence of the strontium isotopic dilution precipitate. Actinide decontamination factors can approach design requirements at high permanganate concentrations.

- A synergism exists between additions of calcium nitrate and sodium permanganate to dramatically increase the strontium and actinide decontamination factors without adversely affecting filterability of the precipitates.

- The kinetics of the actinide and strontium removal of the permanganate decontamination process is rapid at moderate temperature $\left(50^{\circ} \mathrm{C}\right)$.

- The relative amounts of precipitating agents and the required decontamination factors may indicate little or no calcium will be required, thus, minimizing cold chemical loading in the glass.

\section{Introduction}

Strontium and the actinide elements $\mathrm{U}, \mathrm{Pu}$ and $\mathrm{Am}$ are present in the High Level Liquid Waste in the Hanford tanks AN-102 and AN-107 due to the presence of complexing agents used in the processes within B Plant. ${ }^{1}$ The proposed BNFL removal processes for strontium and transuranic components from the $\mathrm{AN}-102$ and $\mathrm{AN}-107$ supernate are coprecipitation methods. In Part A, tests were performed to decontaminate real waste samples using natural strontium nitrate in an isotopic dilution and ferric nitrate to coprecipitate the actinides. ${ }^{2-5}$ This work was based on earlier investigations by Herting ${ }^{6}$ and Orth, $e t a l .^{7}$ In general, the results of the experiments indicated a successful decontamination for Sr-90 and the actinides. However, the liquid/solid separation was accomplished by centrifugation. 
Previous studies at the Savannah River Technology Center (SRTC) ${ }^{8,9}$ examined various aspects of the precipitation process such as addition rate, reagent concentrations, free hydroxide level, organic complexant concentration, and temperature using simulated waste solution (see Appendix 1 for composition). The results of these studies gained insight into the chemistry affecting the effectiveness of the precipitation in terms of decontamination and filterability. However, the presence of the organic complexing agents renders the ferric precipitates poorly filterable.

SRTC has performed testing of alternative technologies for the removal of transuranium elements from the chelant-containing wastes. The basis for the work was predominately of Orth. ${ }^{7}$ The decontamination agents used in these experiments were mixtures of ferric/ferrous, nickel (II), cobalt (II), cobalt (III), lanthanum, ${ }^{8}$ and uranyl ion.

Additionally, the application of freshly prepared manganese oxide surfaces has been shown to selectively adsorb lanthanides, ${ }^{11}$ actinides, ${ }^{12}$ and other radionuclides. ${ }^{13,14}$ The manganese dioxide produced by the reduction of permanganate has also been shown to adsorb organic molecules from aqueous solution. ${ }^{15}$ This adsorption property could potentially be used in the decontamination of the chelant-containing wastes at Hanford. Of further interest is the synergistic effect of calcium on the adsorption of organic material on manganese dioxide in wastewater clarification processes. ${ }^{16}$ Therefore, a series of experiments were conducted to examine these effects on transuranium decontamination of an AN-107 waste simulant.

\section{Experimental}

Approximately $50 \mathrm{~mL}$ of the simulant (Appendix 1) was placed into a 200-mL beaker or $125-\mathrm{mL}$ serum vial. The simulant had been adjusted to the hydroxide and aluminum concentration specified in Table 1 . The solution was stirred with a magnetic stirrer and then heated to the required temperature in a water bath on a heater/stirrer plate. An aliquot of the precipitating agent was added. The precipitate slurry was stirred for 15 minutes at temperature prior to the addition of the second precipitating agent. After the second addition, the slurry was stirred for 15 minutes, heated for a specified time in either the water bath or in a temperature-controlled oven. The samples were allowed to cool to room temperature and filtered through a 0.45-micron filter: The filtrate was collected for 1 minute and weighed or volumetrically measured. After the samples had cooled, the remaining slurry was filtered. Samples were submitted to the Analytical Development Section of SRTC for analyses. ${ }^{17}$ The analyses included liquid scintillation analysis for strontium $-90^{18}$ and alpha pulse height analysis. ${ }^{19}$

In performing the plutonium analyses, the samples were subjected to a thenoyltrifluoroacetone (TTA) separation. An aliquot of the sample was initially spiked with a $\mathrm{Pu}-238$ tracer. All of the plutonium in the sample was reduced, an anion complexing agent (aluminum nitrate) was then added. The plutonium in the sample was then oxidized to a +4 oxidation state. The plutonium (IV) was then extracted from the 
matrix using a TTA solution. The TTA layer was mounted in a counting dish and analyzed by alpha spectroscopy. A blank sample was run with the batch of samples.

Table 1. Experimental Conditions

$\begin{array}{ll}\text { Sodium Ion Concentration } & 5.5 \mathrm{M} \\ \text { Hydroxide Ion Concentration } & 1.0 \mathrm{M} \\ \text { Aluminate Ion Concentration } & 0.4 \mathrm{M} \\ \text { Temperature } & 50^{\circ} \mathrm{C}\end{array}$

The analysis results for the Pu-239 alpha peak were yielded using the Pu-238 recoveries from the Pu-238 tracer solution. As the Pu-239 spike solution used was a sample of weapons grade plutonium, a correction was required for the $\mathrm{Pu}-238$ activity inherent to the weapons grade material. A sample of the stock weapons grade plutonium was analyzed for a Pu-239/240 to Pu-238 ratio. This ratio was used to correct the separation yields.

\section{Results and Discussion}

\section{Addition Ferric and Ferrous Precipitation Studies}

The results from the statistically designed experiments showed filterability and decontamination for the strontium nitrate/ferric nitrate to be too low for practical use. The BNFL Inc. basis of design for the filtration process assumes a filter flux rate of $\geq 1$ $\mathrm{gpm} / \mathrm{ft}^{2}$ can be achieved using $0.1 \mu \mathrm{m}$ sintered metal filter elements. The use of other iron precipitating agents may prove more useful. Therefore, a series of tests were conducted to determine if mixed valence precipitates of iron were conducive to use in the Sr/TRU removal step. Additionally, oxalic acid and lanthanum nitrate reagents were examined as possible replacement of the ferric nitrate. In these studies, the focus was actinide removal; therefore, no strontium isotopic dilution was performed.

Figure 1 contains the decontamination data calculated from the Sr-85 and Am-241 radiotracer measurements. The decontamination factor (DF) required for the flowsheet is 5. The ferric/ferrous mixture did not enhance the americium removal. The mixed valence precipitate was magnetic and did filter slightly better. The inability of iron (III) to affect an actinide DF directs the research to other agents. The inability of lanthanum 
W. R. Wilmarth, et al.

(III) to displace the americium ions from the complexing agents is a little surprising based on the higher charge density of La (III) vs. Am (III).

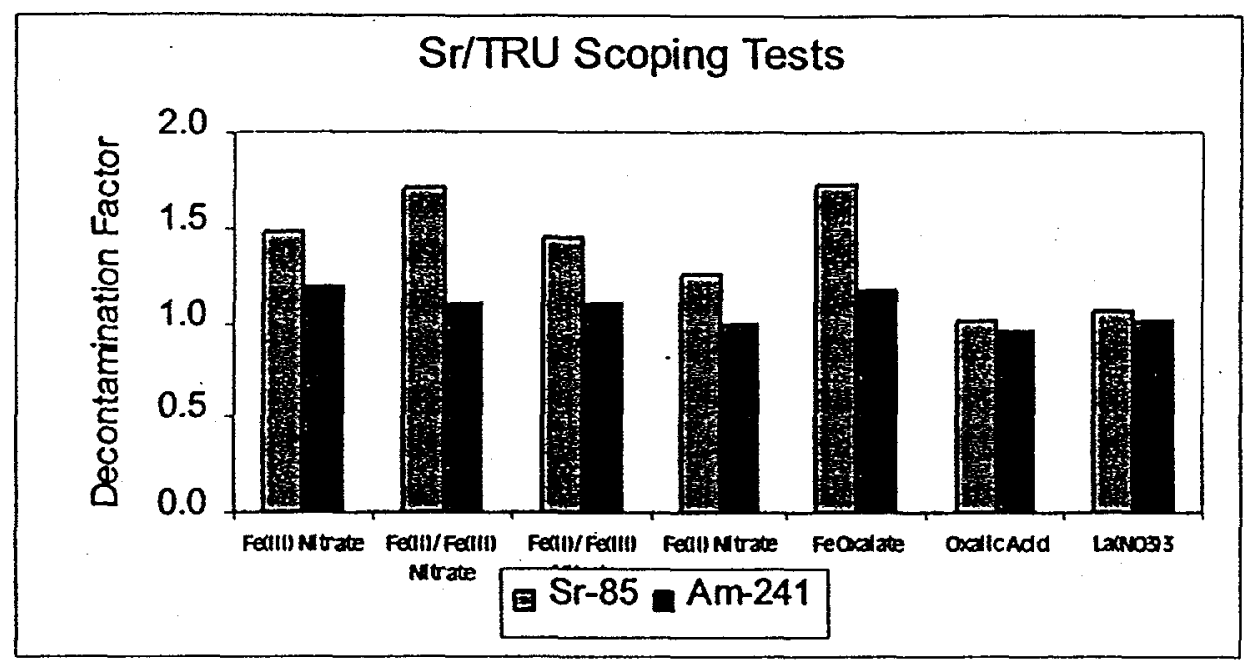

Figure 1. Decontamination Factors for Ferric/Ferrous Precipitations

\section{Effect of Other Transition Metal Agents and Calcium}

The ethylenediaminetetraacetic acid (EDTA) complexing agent is well known in the inorganic literature to bind to many different transition metals such as $\mathrm{Ca}(\mathrm{II}), \mathrm{Fe}$ (II), $\mathrm{Ni}$ (II) and $\mathrm{Co}$ (III). If the actinide is complexed by EDTA these metals could potentially be effective decontamination agents. Therefore, metals having high affinity for EDTA may remove the actinides from solution by substitution. A series of tests were performed to measure actinide and strontium DFs for a variety of agents. The filterability of the resultant precipitates was also measured. These tests used a strontium nitrate addition to aid the $\mathrm{Sr}-85$ decontamination.

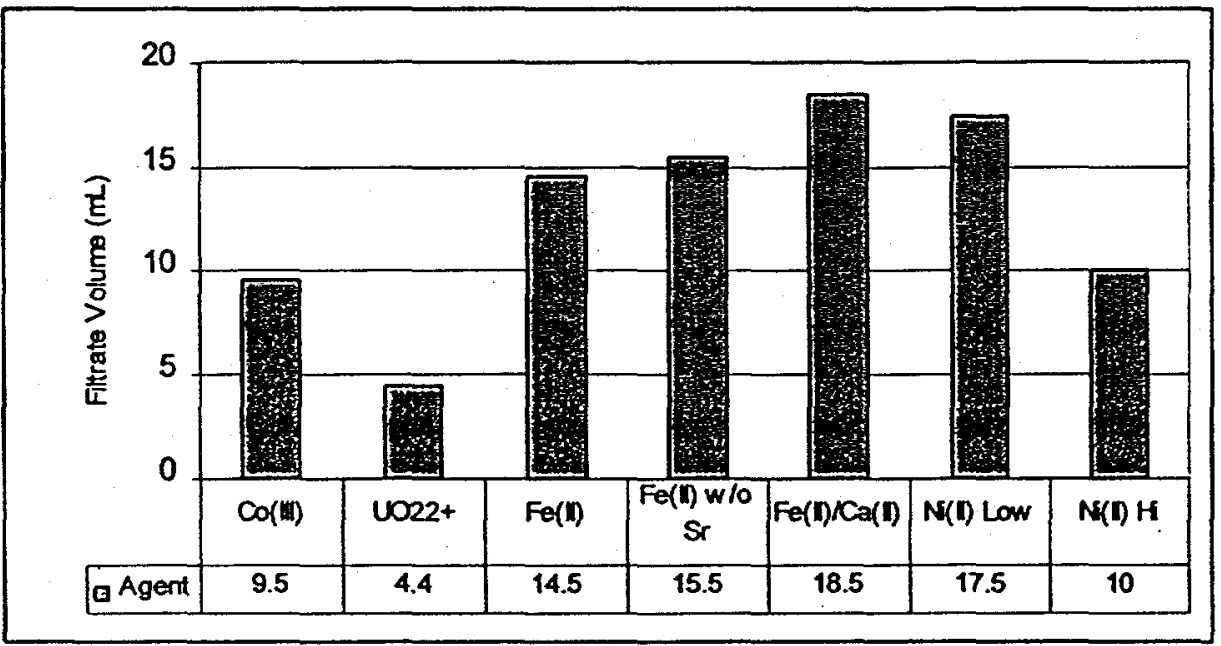

Figure 2. Filtration Volumes from Transition Tests 
Figure 2 shows the filtration data collected in a one minute interval from the tests employing $\mathrm{Fe}$ (II), $\mathrm{Co}$ (III), $\mathrm{Ni}$ (II) and uranyl ion. Filtration volumes ranged from 4.4 $\mathrm{mL}$ to $18.5 \mathrm{~mL}$. These fluxes are low and probably unsuitable for use in the decontamination process. However, the ferrous tests show that the addition of calcium $(0.0375 \mathrm{M})$ does not significantly decrease the filtration flux, when combined with the ferric nitrate.

The decontamination factors for Sr-85, Pu-239 and Am-241 are shown in Figure 3. Strontium decontamination was successfully attained by isotopic dilution for all of the samples. The Sr DFs for the nickel experiments were multiplied by 0.1 to fit on the scale. The actual DFs were 97.7 and 98 for the low concentration $(0.0375 \mathrm{M})$ and the high concentration $(0.075 \mathrm{M})$, respectively. The actinide factors were low with the exception of the calcium $(0.0375 \mathrm{M})$ and ferrous $(0.0375 \mathrm{M})$ mixture. The calcium addition increased the $\mathrm{DF}$ for the actinide from 1.2 to $8-10$. Both americium and plutonium were almost equally affected by this addition. Because of the low filterability of this precipitate the use of this mixture is not very attractive. However, the use of calcium addition to sequester the chelant may have other uses.

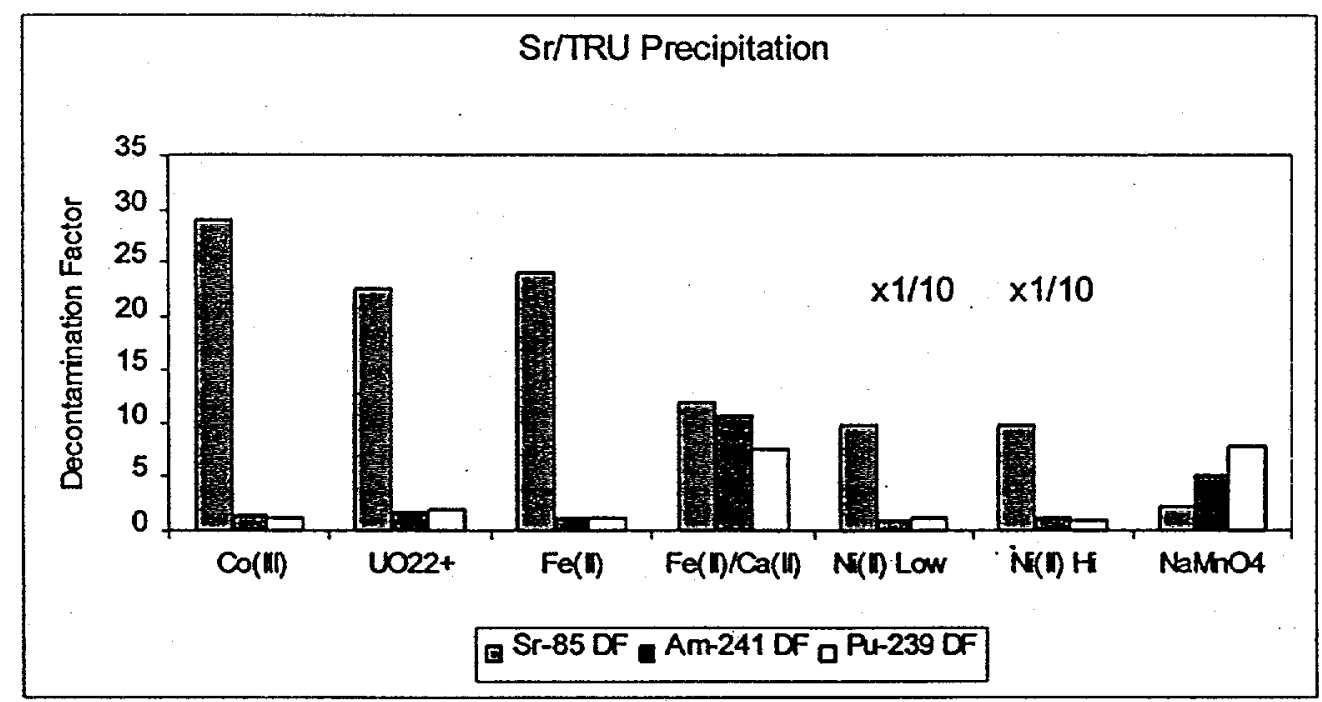

Figure 3. Decontamination Factors for Other Transition Metals

\section{Initial Testing with Sodium Permanganate and Calcium Decontamination}

$\mathrm{Orth}^{7}$ had originally examined the use of potassium permanganate for strontium decontamination of a 101-SY simulant and found decontamination factors on the order of $10-20$. A permanganate test with an actual sample from 101-SY showed plutonium decontamination in addition to the strontium removal. The applicability of this process to the complexant concentrated waste (AN-102 and AN-107) was worthy of testing. 
Shown in Figure 4 are the filtrate volumes $(\mathrm{mL})$ obtained after four separate tests of adding various levels of calcium and sodium permanganate to the AN-107 simulant along with the $0.075 \mathrm{M}$ strontium nitrate isotopic dilution. These volumes were obtained after one minute of filtering through a 0.45 -micron cellulose nitrate filter. Filtrate volumes were high and range from 9 to $25 \mathrm{~mL}$. The precipitate prepared by the addition of $0.2 \mathrm{M}$ $\mathrm{Ca}\left(\mathrm{NO}_{3}\right)_{2}$ filtered the best. Addition of $0.075 \mathrm{M} \mathrm{NaMnO}_{4}$ reduced the filterability $(16$ $\mathrm{mL}$ ) in reference to the calcium precipitate. Addition of $0.0375 \mathrm{M}$ calcium and $0.075 \mathrm{M}$ permanganate exhibited the same filterability as the $0.075 \mathrm{M}$ permanganate alone. Ironically, dramatically reducing the calcium and permanganate with the $0.075 \mathrm{M}$ strontium caused the solution to filter relatively poorly.

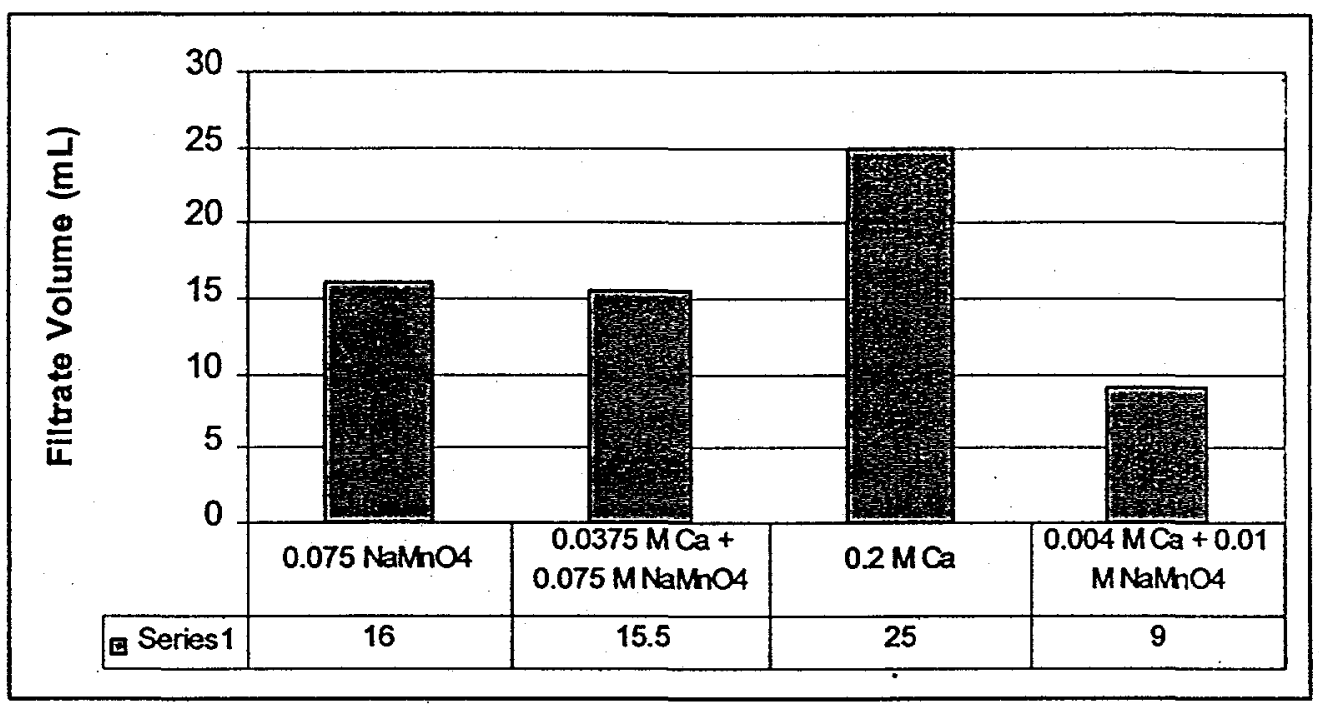

Figure 4. Filterability of Permanganate and Calcium Precipitates

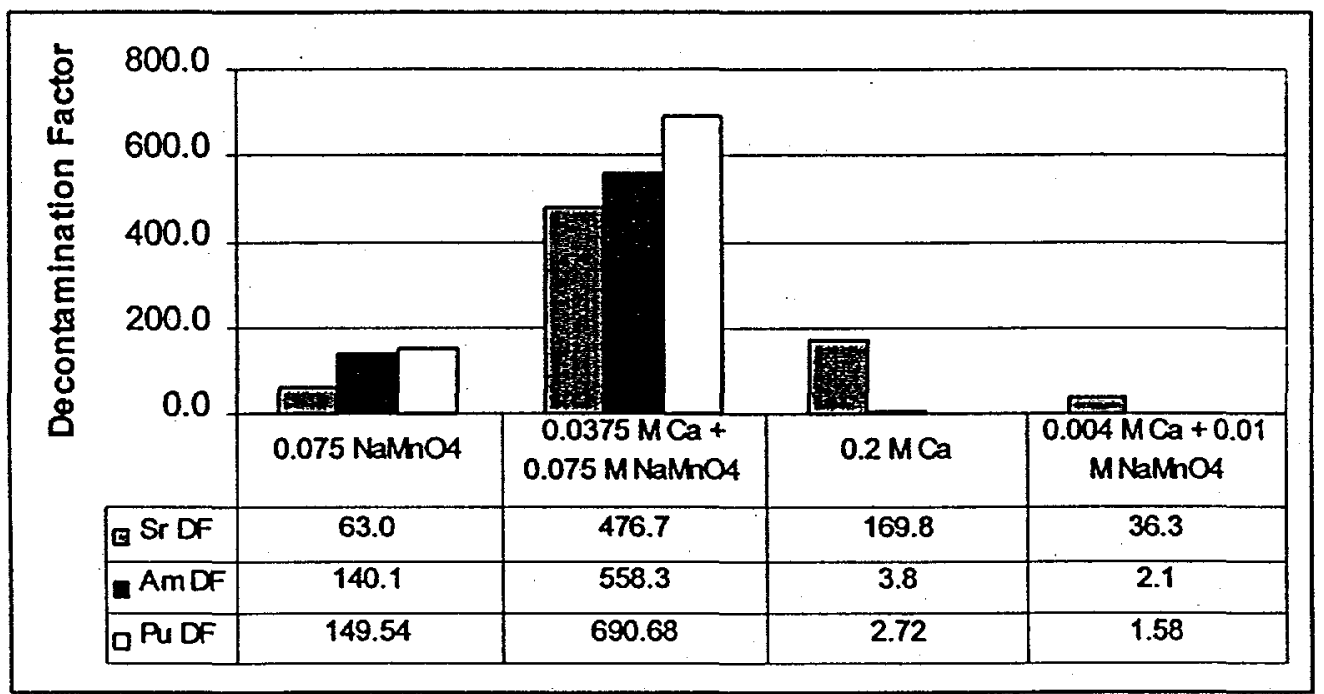

Figure 5. Decontamination Factors for Permanganate and Calcium Additions 
The decontamination factors calculated from the measured Sr-85, Am-241 and Pu-239 concentrations are shown in Figure 5. Remembering the required DFs are 10 for $\mathrm{Sr}$ and 5 for $\mathrm{Am}$ and $\mathrm{Pu}$, the DFs obtained from the addition of $0.075 \mathrm{M}$ sodium permanganate far exceed the requirements. The DFs obtained were 60,140 and 150 for $\mathrm{Sr}, \mathrm{Am}$ and $\mathrm{Pu}$, respectively. The addition of $0.2 \mathrm{M}$ calcium nitrate to the solution along with the strontium isotopic dilution gave acceptable DF for $\mathrm{Sr}(170)$ but unacceptable DF for Am (3) and $\mathrm{Pu}(2.7)$. However, the combination of calcium and permanganate along with the strontium dilution exhibited a very large DF for each species. This synergism between $\mathrm{Ca}, \mathrm{Sr}$ and $\mathrm{MnO}_{4}{ }^{-}$gave DFs of $470 \mathrm{for} \mathrm{Sr}, 550$ for $\mathrm{Am}$ and 690 for $\mathrm{Pu}$. A subsequent test at one tenth the addition level for calcium $(0.004 \mathrm{M})$ and permanganate $(0.01 \mathrm{M})$ showed greater than an order of magnitude reduction in the actinide DF. These results along with the good filterability data suggest the addition of calcium and permanganate along with the strontium isotopic dilution could be a potential replacement for the strontium and ferric nitrate flowsheet for treating the complex concentrate waste (AN-102 and AN-107 tanks).

\section{Additional Calcium/Permanganate Tests}

The results of the initial tests on calcium and permanganate addition for actinide removal and strontium addition for isotopic dilution for strontium removal were very encouraging. Therefore, additional tests were conducted at two calcium levels $(0.0375 \mathrm{M}$ and $0.02 \mathrm{M})$ along with three permanganate levels $(0.02 \mathrm{M}, 0.04 \mathrm{M}$, and $0.06 \mathrm{M})$ to examine filterability and decontamination levels in order to begin to optimize the minimum cold chemical feed. The results of the filtration data are shown in Figure 6. The filtrate volumes obtained after one minute through a 0.45 micron filter are the highest obtained during the Sr/TRU precipitation testing. The volumes were very near $30 \mathrm{~mL}$ or approximately $60 \%$ of the liquid that was clarified in one minute.

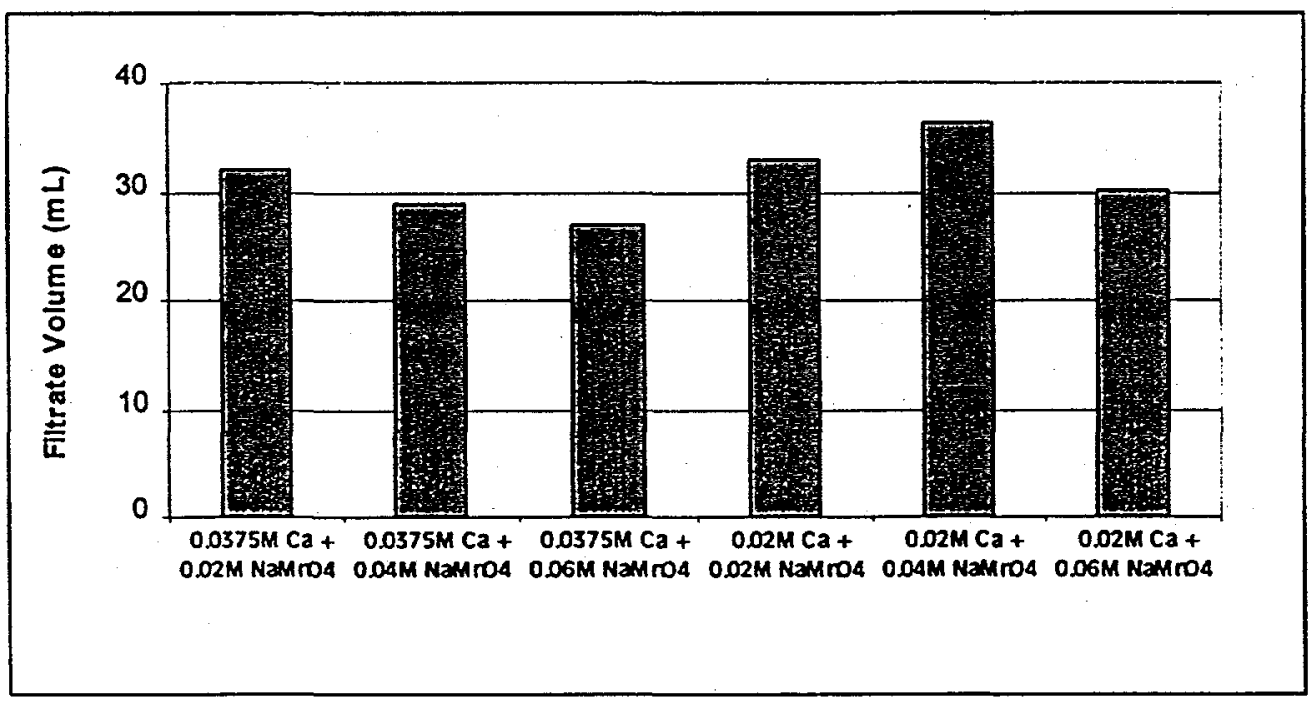

Figure 6. Filtrate Volume $(\mathrm{mL})$ from 2 Level Calcium Tests 
Figure 7 contains the decontamination data for the addition calcium and permanganate tests. The tests were conducted at the high calcium level $(0.0375 \mathrm{M})$ exhibit sufficient $\mathrm{DF}$ for all of the species ( $\mathrm{Sr}, \mathrm{Am}$, and $\mathrm{Pu}$ ). There is a direct relationship between the DF observed for each species with increasing permanganate. Increasing the permanganate concentration to $0.06 \mathrm{M}$ raised the americium DF to $\sim 240$ and the plutonium $\mathrm{DF}$ to $\sim 60$. The strontium DF increased with increasing permanganate concentration; however, the effect was not as large. At the lower calcium level $(0.02 \mathrm{M})$, the same effects are observed. Actinide DFs increase with increasing permanganate concentration.

Acceptable DFs for each species were obtained at mid permanganate concentration $(0.02$ $\mathrm{M} \mathrm{Ca}$ and $0.04 \mathrm{M} \mathrm{MnO}_{4}{ }^{-}$). Shown in Figure 8 is a statistical fit of the of the $\ln$ (DF) for americium as a function of permanganate concentration. Using this equation, the permanganate concentration needed to obtained the required americium DF (5) would be $0.022 \mathrm{M}$ sodium permanganate at the $0.02 \mathrm{M}$ calcium concentration.

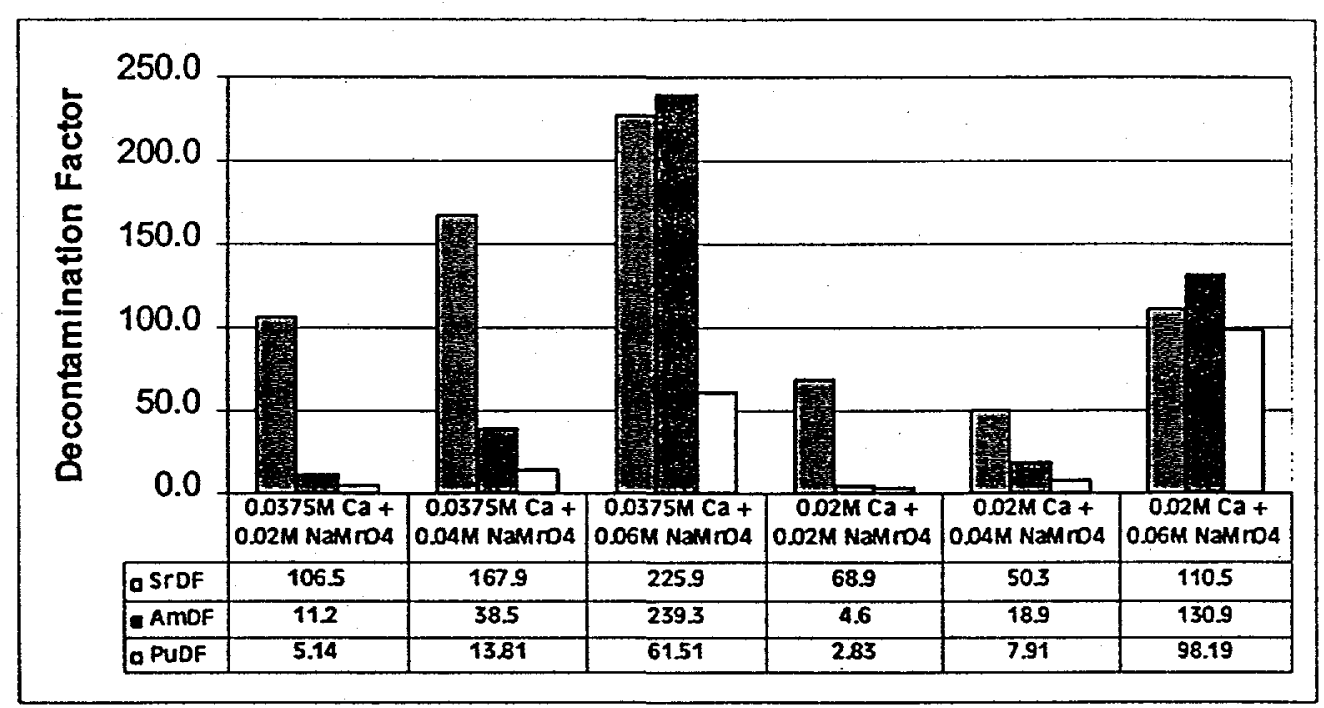

Figure 7. Decontamination Factors for Additional Calcium and Permanganate Tests

These tests clearly show the positive effect of increased permanganate addition for the removal of actinide species from the AN-107 simulant. Additional examination of the data shows a direct influence of the calcium concentration. For each permanganate level $(0.02,0.04$ and $0.06 \mathrm{M})$, the calculated ratio of the actinide DF at $0.0375 \mathrm{M}$ Ca to the DF at $0.02 \mathrm{M} \mathrm{Ca}$ is shown in Table 2. With the exception of the plutonium ratio at the very . high permanganate level $(0.06 \mathrm{M})$, reducing the calcium level by 2 reduced the actinide DF by $\sim 2$. 


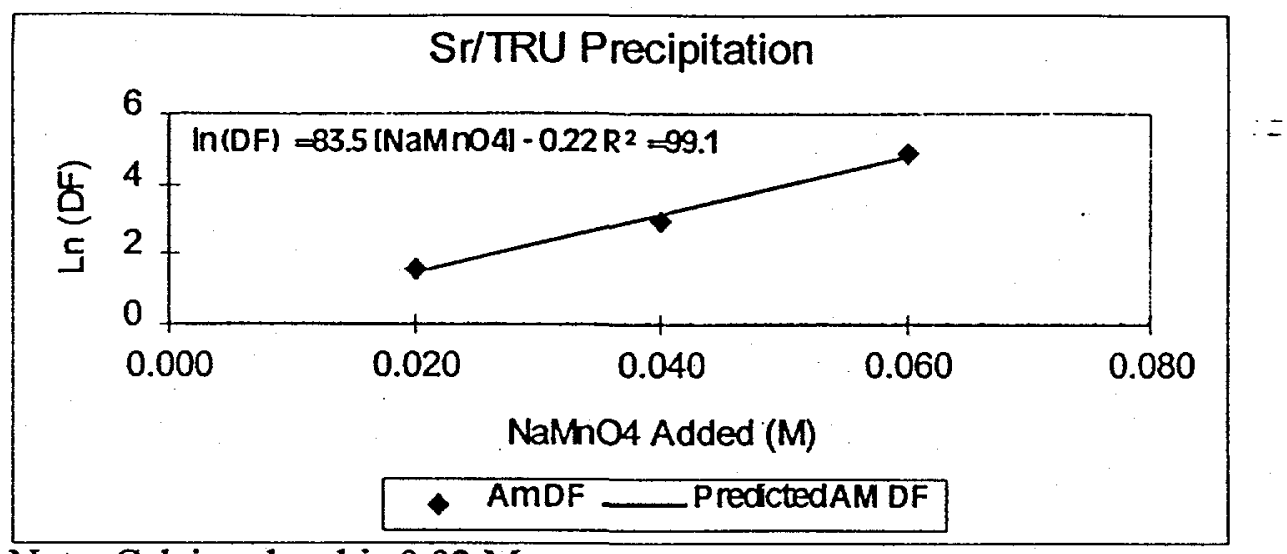

Note: Calcium level is $0.02 \mathrm{M}$.

Figure 8. Statistical Fit of Am DF Data

Table 2. Comparison of Actinide DFs at Two Calcium Levels

DF Ratio for $0.0375 \mathrm{M} \mathrm{Ca}$ to $0.02 \mathrm{M} \mathrm{Ca}$

$\begin{array}{ccc}\text { Permanganate Level } & \text { Am } & \mathrm{Pu} \\ 0.02 \mathrm{M} & 2.4 & 1.8 \\ 0.04 \mathrm{M} & 2.0 & 1.7 \\ 0.06 \mathrm{M} & 2.2 & 0.6\end{array}$

Rate of Actinide Removal in Calcium/Sodium Permanganate Decontamination

The rate of removal of the actinides is important to understand to support engineering and design of the plant. All of the pervious tests were conducted for 4 hours with sampling only at the end of the experiment. Therefore, a kinetic study was performed using the 5.5 $M$ sodium AN-107 simulant. The level of strontium, calcium and permanganate additions was $0.075 \mathrm{M}, 0.0375 \mathrm{M}$ and $0.04 \mathrm{M}$, respectively. The temperature was $50^{\circ} \mathrm{C}$.

Shown in Figure 9 are the $\mathrm{Sr}-85$ and Am-24l concentrations in the liquid phase plotted as a function of time. There is a very rapid drop in the radionuclide concentration in the 
first 0.5 hours. A slower, steady reduction in the radionuclide concentration is then observed for the remainder of the test. There is no visible evidence of permanganate existing after addition. It appears as though the permanganate reacts and the freshly produced solids continue to absorb the radionuclides. The adsorption is very linear as can be seen in Figure 10. An additional order of magnitude of the DF is obtained for each additional hour at $50^{\circ} \mathrm{C}$. This behavior is typical of an adsorption process. Serrano and Garcia ${ }^{11}$ had experimentally measured Ce-141 Freundlich adsorption isotherms. The Sr-85 and Am-241 behavior is probably very similar.

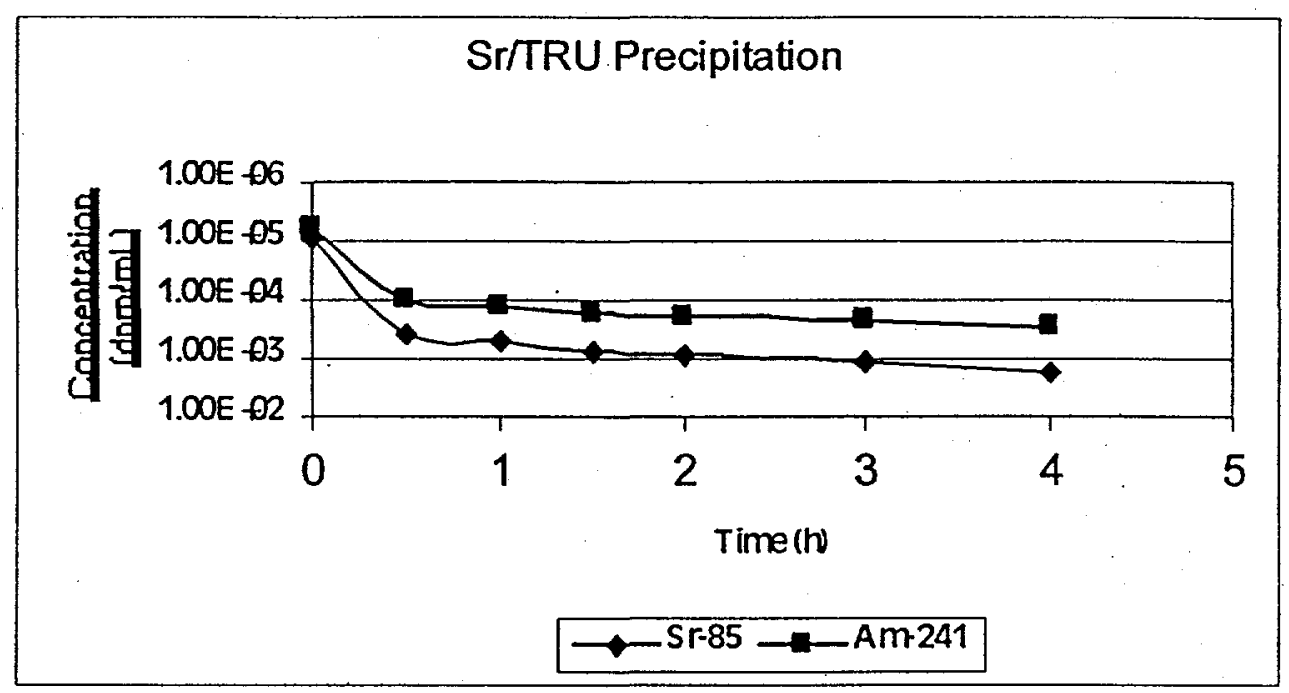

Figure 9. Kinetic Data for Permanganate Decontamination

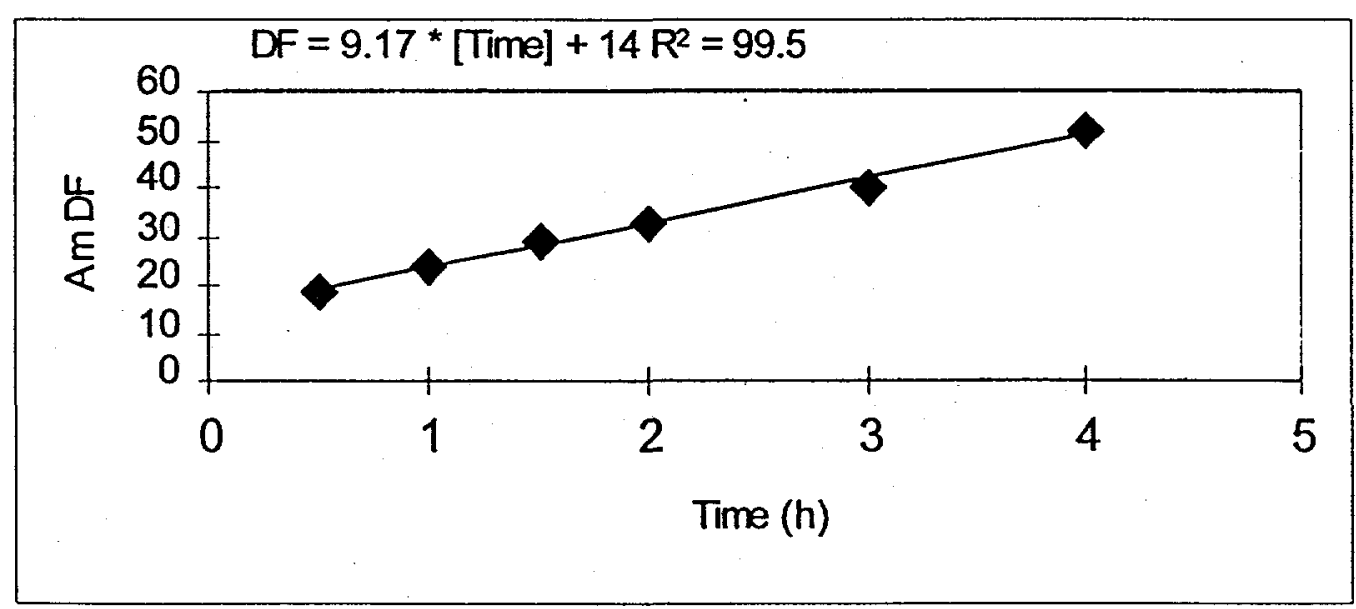

Figure 10. Statistical Analysis of Am DF 


\section{Conclusions}

Removal of strontium from the complexant-containing waste (AN-102 and AN-107) had previously been acceptably accomplished by isotopic dilution. Actinide removal üsing ferric co-precipitation, however, was very problematic from both a processing and a decontamination standpoint. Various other transition metals were examined for replacement of the ferric hydroxide precipitation.

This work has identified and tested a sodium permanganate reaction that produces a precipitate that is readily filterable and provides sufficient decontamination of the actinides from an $\mathrm{AN}-107$ simulant at a modest operating temperature $\left(50^{\circ} \mathrm{C}\right)$. Additionally, the work has identified a positive synergist effect of adding calcium nitrate prior to the addition of sodium permanganate. This synergism can increase both the actinide DF and strontium DF. Optimization of this process could potentially lead to a reduced cold chemical feed while meeting decontamination requirements and within the flowsheet time restraints.

The following recommendations arise from the results of this work:

- Testing with actual tank waste samples should be conducted to verify observations/test results with simulated waste solutions.

- Effects on glass composition should be evaluated for this precipitation process.

- BNFL Inc. must store the Sr/TRU precipitate for a period of time before blending with the high level waste sludge. Therefore, the long-term stability of the SR/TRU precipitate should be evaluated.

\section{Acknowledgements}

The authors wish to acknowledge the help and assistance provided by the Analytical Development Section in their analysis of the many samples submitted during this work. Additionally, Vicki Dukes in the preparation and handling of the samples performed an excellent job.

\section{$\underline{\text { References }}$}

1. M. J. Klein and W. G. Wilson, "Strontium Recovery from Purex Acidified Sludge," ARH-CD-691, May 1976.

2. D. J. McCabe, "Hanford Envelope Archive C Tank Waste Precipitation Study (U)," SRTC-BNFL-004, Revision 0, March 20, 1997.

3. D. J. McCabe, "Hanford C Tank Waste Precipitation Study (U)," SRTC-BNFL-005, Rev. 2, August 13, 1997. 
4. D. J. McCabe, "Hanford Simulant Tank Waste Precipitation Study," SRTC-BNFL006, Rev. 0, April 22, 1997.

5. D. J. McCabe, "Hanford Envelope C Tank Waste Precipitation Optimization Study (U)," SRTC-BNFL-011, Rev. 0, August 13, 1997.

6. D. L. Herting, "Report of Scouting Study on Precipitation of Strontium, Plutonium and Americium from Hanford Complexant Concentrate Waste," WHC-SD-WMDTR-040, Rev. 0, 1995.

7. R. J. Orth, A. H. Zacher, A. J. Schmidt, M. R. Elmore, K. R. Elliott, G. G. Neuenschwander, S. R. Gano, "Removal of Strontium and Tranuranics from Hanford Tank Waste via Addition of Metal Cations and Chemical Oxidant - FY1995 Test Results," PNL-10766, UC-721, September, 1995.

8. W. R. Wilmarth, R. E. Eibling, C. A. Nash, and T. B. Edwards, "Phase I and II Results from Sr and TRU Precipitation Tests," BNF-003-98-00180, September 15, 1999.

9. W. R. Wilmarth, "Preliminary Results of Rate of Delivery Experiments for Envelope C Simulant", BNF-003-98-0023, November 5, 1998.

10. H. L. Recht and M Ghassemi, "Phosphate Removal from Wastewaters using Lanthanum Precipitation," Wastewater Pollution Control research Series 17010EFX, April, 1970.

11. J. Serrano G. and O. C. Garcia D., "Ce ${ }^{3+}$ Adsorption on Hydrated $\mathrm{MnO}_{2}$," J. Radioanalytical and Nuclear Chemistry, 230, 33 (1998).

12.V. N. Yepimakhov and S. V. Gkuhkov, "Determination of U, Pu, Am and Cm in water Coolant of Nuclear Power Plants using Membranes Impregnated with Hydrated Manganese Dioxide,"," J. Radioanalytical and Nuclear Chemistry, 232, 163 (1998).

13.G. Koulouris, Sorption and Distribution of ${ }^{226} \mathrm{Ra}$ in an Electroytic Manganese Dioxide Column in the Presence of Other Ions," J. Radioanal. Nucl. Chem. Letters, $\underline{212}, 131$ (1996).

14.P. H. Towler, J. D. Smith, and D. R. Dixon, "Magnetic Recovery of Radium, Lead, and Polonium from Seawater Samples after Preconentration on a Magnetic Adsorbent of Manganese Dioxide coated Magnetite," Analytica Chimica Acta, $\underline{328}, 53$ (1996).

15.J. M. Colhurst and P. C. Singer, "Removing Trichloromethane Pecursors by Permanganate Oxidation and Manganese Dioxide Adsoption," Research and Technology, February, 1982, P. 78. 
W. R. Wilmarth, et al.

16. P. K Goel, M. Chaudhuri, “ Manganese-aided Lime Clarification of Municipal Wastewater," Wat. Res., 30, 1548 (1996).

17. "Obtaining Analytical Services, "Manual L1, Procedure 3.07, Rev. 0, August 6, 1993.

18. "Gamma Sample Preparation and Analysis (Gamma PHA)," Manual L16.1, Procedure ADS-2420, Rev. 3, July 28, 1997.

19. “Alpha Pulse Height Analysis," Manual L16.1, Procedure ADS-2402, Rev. 2, July $25,1994$. 
W. R. Wilmarth, et al.

$\dot{B} N F-\Delta \Delta 3-98-\Delta / 6 \Delta$

BNF-98-003-160

Page 18 of 20

\section{Approvals}

Author

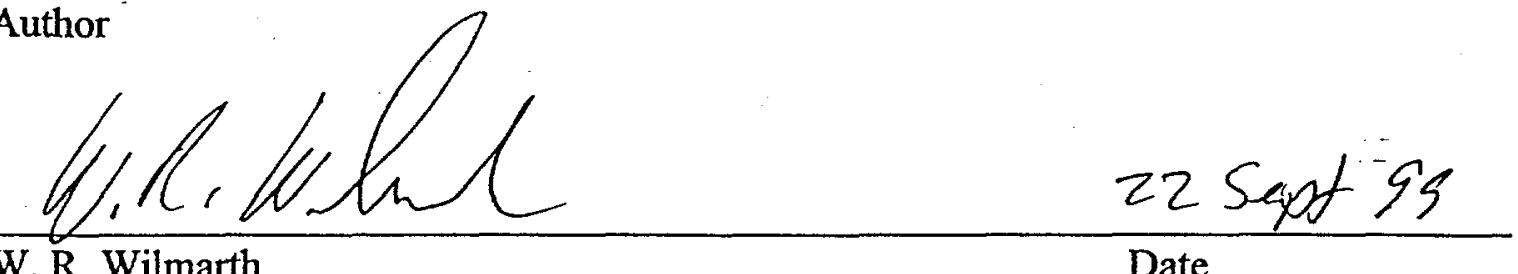

Waste Processing Technology

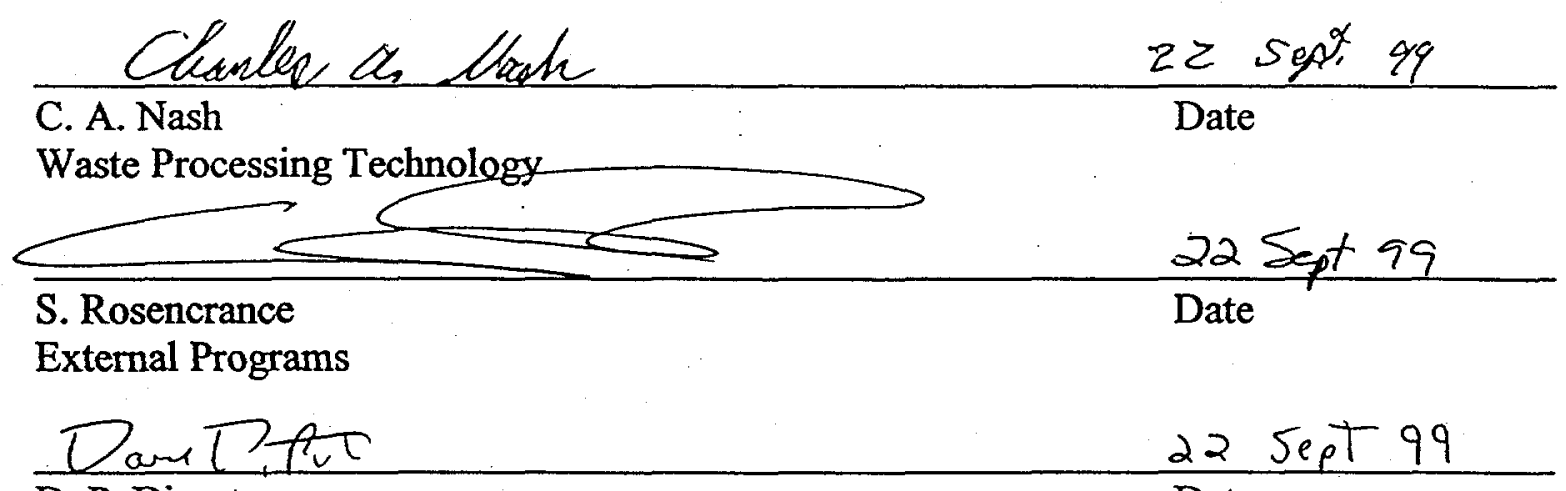

D. P. Diprete

Date

Analytical Development

andarest

C. C. Diprete

Date

Analytical Development

Design Check

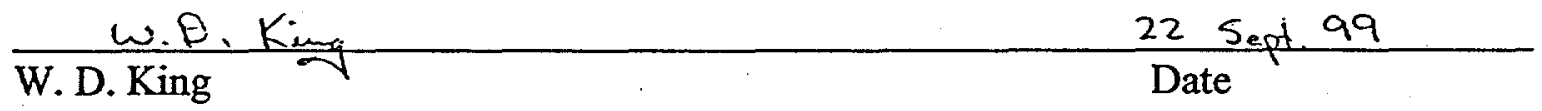

External Programs

Management

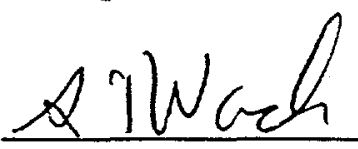

$10 / 25 / 99$

S. T. Wach, Manager

Date

External Programs

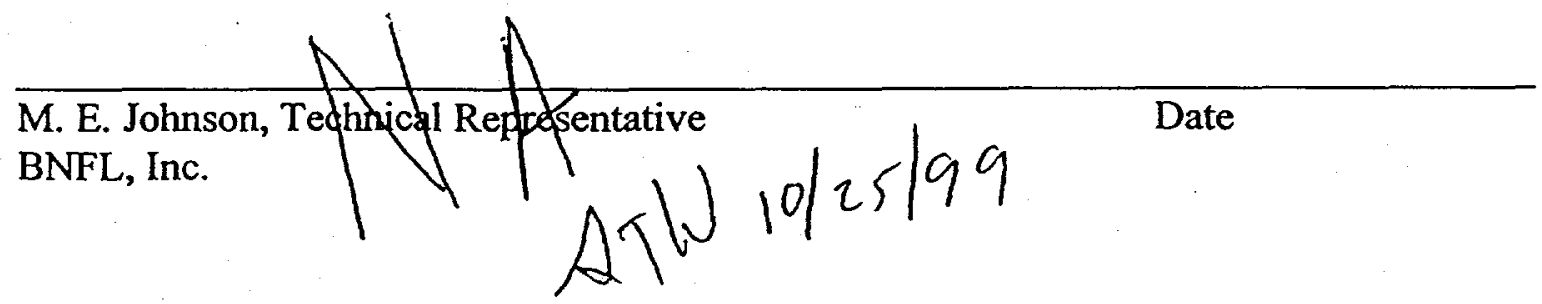


W. R. Wilmarth, et al.

\section{Appendix 1. AN-107 Simulant Composition}

\begin{tabular}{|c|c|c|c|}
\hline Component & Molecular weight & Concentration Units & Concentration \\
\hline Acetate & 59.04462 & $1100 \mathrm{mg} / \mathrm{Liter}$ & $1.86 \mathrm{E}-02 \mathrm{M}$ \\
\hline Aluminum & 26.98154 & 386 mg/iter & $1.43 \mathrm{E}-02 \mathrm{M}$ \\
\hline Ammonium & 18.03846 & $22 \mathrm{mg} /$ hiter & $1.22 \mathrm{E}-03 \mathrm{M}$ \\
\hline Barium & 137.33 & 7 mg几iter & $5.42 \mathrm{E}-05 \mathrm{M}$ \\
\hline Boron & 10.81 & $35 \mathrm{mg}$ Liter & $3.24 E-03 M$ \\
\hline Bromide & 79.904 & 1150 mg/Liter & $1.44 E-02 M$ \\
\hline Cadmium & 112.41 & 64 mg/Liter & $5.70 E-04 M$ \\
\hline Calcium & 40.08 & $591 \mathrm{mg} /$ Liter & 1.47E-02 M \\
\hline Carbonate & 60.0092 & 83936 mg/iter & $1.40 \mathrm{E}+00 \mathrm{M}$ \\
\hline Cerium & 140.12 & 53 mg/Liter & 3.77E-04 M \\
\hline Chloride & 35.453 & $1830 \mathrm{mg}$ /Liter & $5.16 E-02 M$ \\
\hline Chromium & 51.996 & 176 mg/Liter & $3.38 \mathrm{E}-03 \mathrm{M}$ \\
\hline Copper & 63.546 & 30 mg/iter & 4.74E-04M \\
\hline $\begin{array}{l}\text { Ethylenediaminete } \\
\text { traacetic acid }\end{array}$ & 288.20824 & 5620 mg Liter & 1.95E-02 M \\
\hline Fluoride & 18.9984 & $133 \mathrm{mg} /$ Liter & $7.00 \mathrm{E}-03 \mathrm{M}$ \\
\hline Formate & 45.01774 & 10400 mg/Liter & 2.31E-01 M \\
\hline Glycolate & 75.04206 & $18600 \mathrm{mg} /$ Liter & 2.48E-01 M \\
\hline Hydroxide & 17.00734 & 340 mg/Liter & 2.00E-02 M \\
\hline Iron & 55.847 & 1690 mg/Liter & 3.03E-02 M \\
\hline Lanthanum & 138.9055 & 46 mgRiter & 3.28E-04M \\
\hline Lead & 207.2 & $388 \mathrm{mg} / \mathrm{Liter}$ & 1.87E-03M \\
\hline Magnesium & 24.305 & 25 mg/liter & 1.03E-03 M \\
\hline Manganese & 54.938 & $563 \mathrm{mg} / \mathrm{hiter}$ & $1.02 E-02 M$ \\
\hline Molybdenum & 95.94 & $36 \mathrm{mg} /$ Liter & 3.73E-04 M \\
\hline Neodymium & 144.24 & $96 \mathrm{mg} /$ Liter & $6.65 \mathrm{E}-04 \mathrm{M}$ \\
\hline $\begin{array}{l}\text { n- } \\
\text { Hydroxyethylenedi } \\
\text { aminetriacetic acid }\end{array}$ & 275.23618 & $2140 \mathrm{mg} / \mathrm{hiter}$ & 7.78E-03 M \\
\hline Nickel & 58.69 & $530 \mathrm{mg} /$ Liter & $9.03 E-03 \mathrm{M}$ \\
\hline Nitrate & 62.0049 & 230000 mg/liter & $3.71 \mathrm{E}+00 \mathrm{M}$ \\
\hline Nitrite & 46.0055 & 61000 mg/iter & $1.33 E+00 M$ \\
\hline Oxalate & 88.0196 & 826 mg/Liter & $9.38 E-03 M$ \\
\hline Phosphate & 94.97136 & $1110 \mathrm{mg}$ /iter & 1.17E-02 M \\
\hline Potassium & 39.0983 & 1810 mg/iter & 4.63E-02 M \\
\hline Selenium & 78.96 & $1 \mathrm{mg}$ /iter & 6.33E-06 M \\
\hline Silicon & 28.0855 & mg/iter & \#VALUE! $\quad M$ \\
\hline Silver & 107.8682 & $14 \mathrm{mg}$ /iter & 1.33E-04 M \\
\hline Sodium & 22.9898 & $195000 \mathrm{mg} /$ Liter & $8.48 \mathrm{E}+00 \mathrm{M}$ \\
\hline Sulfate & 96.0576 & $8250 \mathrm{mg} / \mathrm{Liter}$ & $8.59 E-02 M$ \\
\hline TIC & 12.011 & $16800 \mathrm{mg} /$ Liter & $1.40 E+00 M$ \\
\hline TOC & & $40400 \mathrm{mg} / \mathrm{Liter}$ & $40.40 \mathrm{~g} \Omega$ \\
\hline Uranium & & $127 \mathrm{mg} / \mathrm{Liter}$ & $1.27 \mathrm{E}+02 \mathrm{ug} / \mathrm{mL}$ \\
\hline Zinc & 65.38 & $45 \mathrm{mg} / \mathrm{Liter}$ & $6.93 E-04 M$ \\
\hline Zirconium & 91.22 & $70 \mathrm{mg} /$ iter & 7.67E-04M \\
\hline
\end{tabular}


W. R. Wilmarth, et al.

$B N F-0 \Delta 3-98-\Delta / 6 \Delta$ BNF-98-003-160

Page 20 of 20

Additional Organics(based upon PNNL Report on FY1997 Results)

Nitrilotriacetic Acid

Citric Acid

Iminodiacetic Acid

188.11618

189.09618

131.08412

Source

Previous PNNL Recipe

Sodium Gluconate
218.14

39265 mg/hiter
$561 \mathrm{mg}$ hiter 8495 mg/iter 5947 mg/Liter
2.98E-03 M

4.49E-02 M

4.54E-02 M

$0.018 M$ 